\title{
Geografia dels conflictes territorials a València i la seua àrea metropolitana*
}

\author{
Luis del Romero Renau \\ Universitat de València. Departament de Geografia \\ luis.romero@uv.es
}

Recepció: juliol de 2014

Acceptació: febrer de 2015

\section{Resum}

Aquest article fa una anàlisi sobre els conflictes territorials sorgits al llarg dels darrers anys, de principis de la dècada de 2000 fins a 2013, a l'àrea metropolitana de València. Amb aquesta anàlisi, volem realitzar una radiografia sobre la conflictivitat territorial d'aquest espai urbà i avançar hipòtesis amb referència a les causes que la van provocar, com també estudiar les connexions espacials que es van establir, de cara a una formulació posterior de recomanacions per a una planificació urbana i territorial i un govern de la ciutat millors. Aquest treball és el resultat d'una recerca sistemàtica sobre conflictes territorials, actors i estratègies en tota mena de disputes relacionades amb l'ús i la gestió de l'espai urbà.

Paraules clau: conflicte territorial; València; planificació territorial; protesta; moviments socials.

Resumen. Geografía de los conflictos territoriales de Valencia y su área metropolitana

Esta investigación realiza un análisis sobre los conflictos territoriales surgidos en los últimos años, desde principios de la década de 2000 hasta 2013, en el área metropolitana de Valencia. Con este análisis, se pretende realizar una radiografía sobre la conflictividad territorial de este espacio urbano y avanzar hipótesis acerca de las causas que la provocaron y las conexiones espaciales que se establecieron, de cara a una formulación posterior de recomendaciones para una planificación urbana y territorial y un gobierno de la ciudad mejores. Este trabajo es el resultado de una investigación sistemática sobre conflictos territoriales, actores y estrategias en todo tipo de disputas relacionadas con el uso y la gestión del espacio urbano.

Palabras clave: conflicto territorial; Valencia; planificación territorial; protesta; movimientos sociales.

* Aquesta recerca ha estat elaborada gràcies a la col-laboració dels estudiants en pràctiques Francisco Linares i Rali Ragitosh. Així mateix, agraeixo els comentaris dels avaluadors per millorar la qualitat del text. 
Résumé. Géographie des conflits territoriaux à Valence et dans son aire métropolitaine

Cette recherche réalise une analyse spatiale des conflits territoriaux des dernières années, depuis le début des années 2000 jusqu'en 2013 dans la région métropolitaine de Valence. Cette analyse réalise une radiographie de la conflictualité territoriale de cet espace urbain et avance des hypothèses sur ses causes et ses connexions spatiales, dans l'objectif de formuler ultérieurement des recommandations pour une meilleure planification urbaine et territorial et pour le gouvernement de la ville. Ce travail est le résultat d'une recherche systématique sur les conflits territoriaux, les acteurs et les stratégies dans tous types de conflits liés à l'utilisation et à la gestion de l'espace urbain.

Mots-clés: conflit territorial; Valence; aménagement du territoire; protestation; mouvements sociaux.

\section{Abstract. Geography of urban and locational conflicts in Valencia and its metropolitan area}

In this study we perform a spatial analysis of the urban and locational conflicts occurring from the early 2000s until 2013 in the metropolitan area of Valencia. We diagnose urban conflictivity in this urban space and put forward a hypothesis about its causes and spatial connections in order to propose recommendations for improving urban and regional planning and city government. This work is the result of systematic research on urban and locational conflicts, stakeholders, and strategies in disputes related to the use and management of urban space.

Keywords: urban conflict; Valencia; spatial planning; protests; social movements.

\section{Sumari}

\section{Introducció}

2. Investigant la conflictivitat urbana i territorial a Espanya

3. Anàlisi de conflictes a l'àrea metropolitana de València
4. El paper de l'Administració

i dels moviments socials

5. Conclusions

Referències bibliogràfiques

Annex 1

Annex 2

\section{Introducció}

Les dues darreres dècades han comportat canvis d'ordre social, econòmic, urbanístic $\mathrm{i}$ ambiental de gran calat per a València $\mathrm{i}$ la seua àrea metropolitana. La ciutat real (no pas l'administrativa) de València ha guanyat en població i, sobretot, en diversitat cultural. Han nascut barris sencers a la calor del boom immobiliari i especulatiu del període 1996-2008; s'han creat grans infraestructures que han millorat l'accessibilitat de la ciutat, però que també han implicat importants impactes territorials, is'han construït projectes «emblemàtics» relacionats o no amb grans esdeveniments que han canviat completament la fisonomia de llocs estratègics com ara el port, algunes de les grans vies de la ciutat, l'horta o la morfologia urbana de poblacions com ara Torrent, Paterna o 
Riba-roja. Evidentment, moltes d'aquestes transformacions han provocat protestes $\mathrm{i}$ han generat conflictes territorials de tot tipus $\mathrm{i}$ intensitat. Tant aquestes dinàmiques territorials (la prolongació de Blasco Ibáñez cap al Cabanyal, les reformes successives del port de València o, en general, el creixement urbanístic desmesurat i caòtic del litoral valencià) com alguns dels conflictes més notoris que han comportat han sigut estudiats de manera monogràfica des d'òptiques i perspectives crítiques distintes (Cucó, 2013; Del Romero, 2010; Gaja, 2013; García i Ruiz, 2013; Lecardane, 2008). Això no obstant, si hi ha una aportació que manca a la literatura geogràfica sobre València és precisament una visió més territorial de la conflictivitat urbana en la qual es puguen posar en relació les diverses conteses territorials sorgides amb el context polític i social predominant durant les darreres dècades a la ciutat i a l'àrea metropolitana.

L'objectiu d'aquest treball és analitzar els conflictes territorials sorgits en els darrers anys, de principis de la dècada de 2000 fins a 2013, a l'àrea metropolitana de València. Amb aquesta anàlisi, volem fer una radiografia sobre la conflictivitat territorial d'aquest espai urbà i avançar hipòtesis sobre les causes que la van provocar i les connexions espacials que s'hi van establir, de cara a una formulació posterior de recomanacions per a una planificació urbana i territorial i un govern de la ciutat millors. El primer apartat del treball realitza un breu repàs a alguns conceptes clau que s'empraran en l'anàlisi duta a terme, a més d'una explicació de la metodologia emprada per a l'elaboració de la base de dades i les limitacions que presenta; el segon i el tercer capítols constitueixen la part central del treball, en la qual es presentaran els resultats principals de l'anàlisi realitzada per a l'àrea metropolitana de València. Finalment, tancarem aquest article amb un apartat de conclusions i una prospectiva per a futures recerques en aquest camp.

\section{Investigant la conflictivitat urbana i territorial a Espanya}

\subsection{Aproximació al concepte de conflicte territorial}

Tal com afirma Newton (1978), la societat és una xarxa plena de tensions i d'interessos incompatibles, de forma que el conflicte és un element inherent, en lloc d'una anomalia o una amenaça de l'ordre social. Per tant, hauria de ser l'absència de conflictes, més que no pas la presència d'aquests, el que hauria de preocupar acadèmics, polítics i planificadors, ja que és un element imprescindible per incentivar la comunicació entre actors oposats (Dahrendorf, 1958). En aquest sentit, l'existència d'un conflicte territorial palesa, en molts casos, situacions d'injustícia ambiental o social, o fins i tot problemes estructurals de l'urbanisme capitalista, com ara dinàmiques de predació de recursos i d'acumulació per despossessió, un dels mecanismes fonamentals de funcionament del sistema capitalista (Harvey, 2005; Dunn, 2007; Del Romero, 2014) i que reforcen aquestes desigualtats i aquestes injustícies. La conflictivitat urbana $\mathrm{i}$ territorial és una senya de disconformitat en molts casos respecte a aquestes dinàmiques, de manera que la inexistència de conflictes en un procés planifi- 
cador o en la gestió d'una ciutat seria, segons la nostra visió, reflex d'un model de govern poc transparent, democràtic o participatiu.

De manera genèrica, podríem definir el conflicte territorial com tota confrontació entre almenys dos actors per l'ús i la gestió del territori. La confrontació pot anar des de la simple discussió en un fórum formal, com ara un parlament o el ple d'un ajuntament, fins a tota mena d'accions violentes, manifestacions o accions de desobediència civil. Aquesta aproximació conceptual és, per tant, ben àmplia i col-loca el focus d'atenció sobre el territori com a recurs en disputa, justament per la seua natura de bé d'ús i condició de riquesa econòmica i patrimonial. A partir d'aquesta definició de conflicte territorial, podríem parlar de multitud de situacions de confrontació que apareixen a la ciutat dia rere dia. Per tant, d'una banda, cal introduir-hi una sèrie d'acotacions per tal de concretar la nostra definició de conflicte territorial i, de l'altra, distingir-lo d'altres tipus de conflictivitat urbana. No es consideren ací, per exemple, tots aquells conflictes que no estiguen directament relacionats amb l'ús del sòl o, de manera més abstracta, amb la gestió urbana de la ciutat. Per tant, en la base de dades de conflictes en la qual s'ha basat aquest article, no s'hi investiguen ni els problemes exclusivament relacionats amb la delinqüència (prostitució, drogues, robatoris), ni els conflictes estrictament laborals (confrontacions entre empreses i treballadors o sindicats), ni les confrontacions purament polítiques (entre càrrecs públics o partits). Ens hem concentrat en les conteses que sorgeixen de processos de planificació urbana, territorial, estratègica o sectorial o dels programes i projectes que se'n deriven. La major part de conflictes territorials estudiats tenen plataformes o grups de ciutadans com a opositors d'un projecte o d'un pla: estructures organitzatives descentralitzades, antijeràrquiques, flexibles $\mathrm{i}$ amb un nivell baix de profesionalització i d'institucionalització (Riechmann, 1995, citat per Alfama et al., 2007: 191). D'altra banda, com a promotors del projecte, se situen administracions d'escales diferents que contemplen el conflicte i la protesta com un obstacle que endarrereix la posada en marxa del projecte o del pla, com una disfunció que impedeix dur-lo a terme en els terminis establerts que ja han estat decidits, especialment pel que es refereix a la localització, la qual és, sovint, el motiu principal de la contesa (Nel.lo, 2003: 48).

L'anàlisi geogràfica dels conflictes territorials com a procés socioespacial no comença a estudiar-se fins a mitjan anys setanta, a partir de casos de localització d'infraestructures i usos del sòl i, més concretament, referits a casos de conflicte NIMBY o LULU (Popper, 1981; Dear, 1992). Es comencen a estudiar exemples de conteses sorgides per projectes o plans urbans que ciutadans $\mathrm{i}$ moviments de protesta consideren que són perjudicials per als seus interessos i la seva qualitat de vida (Janelle i Millward, 1976; Janelle, 1977; Cox, 1978; Ley i Mercer, 1980; Cox i Johnston, 1982). Molts d'aquests treballs tracten de relacionar l'aparició de conflictes amb el context social, econòmic i polític que caracteritza el territori on sorgeixen, i especialment se centren en protestes contra la localització d'una infraestructura o d'un equipament, on s'enmarquen els conflictes NIMBY (Brion, 1988; Dear, 1992). Més tard, i ja dins del 
context europeu, moltes recerques sobre enfrontaments territorials se centren en l'estudi de grans plans que són qüestionats, a causa de les implicacions socials, ambientals o econòmiques que comporten, per part de moviments més o menys organitzats, en una perspectiva i una escala més àmplia que la localització d'un ús del sòl o d'un equipament (Bobbio i Zeppetella, 1999; Nel.lo, 2003; Lecourt i Baudelle, 2004). A Espanya, Del Moral és un dels primers autors que parla de conflictivitat territorial, però aplicat a un recurs natural com és l'aigua (Del Moral, 1994). Aquest autor relaciona la conflictivitat hídrica amb un marc normatiu que no aborda adequadament la seua entitat com a element natural i com a recurs econòmic alhora. El territori mostra unes contradiccions semblants, tal com assenyala un dels primers autors en fer un estudi monogràfic sobre conflictivitat territorial a Catalunya (Nel.lo, 2003), en el qual s'aborda una sèrie de conflictes, quasi sempre lligats a la promoció de projectes d'infraestructures, plans urbans o altres polítiques sectorials en el context dels anys del boom immobiliari.

En el cas del País Valencià, els primers conflictes territorials daten, com a mínim, de la dècada de 1970, quan comencen a sorgir mobilitzacions ciutadanes que reclamen tot tipus de millores per als barris, especialment accés a un habitatge digne i serveis bàsics, en un context d'auge de les associacions veïnals i després de dècades de desert social imposat per la dictadura franquista (Torres, 2004). Un precedent molt important en aquesta època va ser la mobilització ciutadana sorgida l'any 1973 contra un projecte d'urbanització al costat del llac de l'Albufera, que donaria inici al moviment ecologista a València (Mateu i Domínguez, 2011). Al llarg de la dècada següent, comencen a multiplicar-se els casos de conflictes territorials i ambientals. Una altra qüestió ben diferent és l'estudi de la conflictivitat territorial, que no s'inicia com a línia de recerca més enllà de la purament periodística fins als anys noranta. Dins de la ciutat de València, un dels primers conflictes estudiats des d'aquesta òptica és el de l'anomenat «solar dels jesuïtes», per la urbanització d'un solar contigu al Jardí Botànic amb torres d'habitatges i un hotel (Dolç i Sancho, 2003), si bé és cert que un dels aspectes que més atrau l'atenció dels investigadors és la proliferació, dins del panorama de moviments socials a la ciutat, del moviment Salvem!, que autors com Sorribes estudien per al cas de València (Sorribes, 2001) i que protagonitzen alguns dels conflictes territorials més rellevants de la ciutat i de la seva àrea metropolitana, com ara la protecció de l'horta, l'ampliació de Blasco Ibáñez al Cabanyal o la destrucció de l'Horta de la Punta. No obstant això, la literatura sobre recerques sistemàtiques sobre conflictes territorials a València encara roman exigua.

\subsection{Metodologia i àrea d'estudi}

La metodologia de recerca sobre conflictes territorials desenvolupada en aquest treball es basa en una base de dades feta amb els programes Access i Excel i dissenyada per l'Observatoire de Conflits Socioterritoriaux du Québec, en Canadà (Trudelle et al., 2004). Es tracta d'una aproximació sistemàtica a l'estudi de 
conflictes tot utilitzant, com a font primària i principal, notícies sobre conteses territorials a la premsa escrita, en especial articles publicats en periòdics locals de 2002 fins a 2013, un total de dotze anys. Es tracta d'una etapa ben diferenciada entre dues fases: uns quants anys d'una certa bonança econòmica (fins al 2007) i un segon període de profunda crisi (entre 2008 i 2013). Les fonts de dades treballades sempre provenen, com a mínim, de dos periòdics diferents, amb l'objectiu d'atenuar, en la mesura del que sigui possible, els biaixos derivats de la ideologia que defensa cadascun. En el cas de València, es va fer un buidatge de totes les notícies relacionades amb conflictes territorials segons la definició proposada en l'apartat anterior entre 2002 i 2013 als diaris Levante i Las Provincias. A més, per a aconseguir dades sobre l'evolució de cada conflicte amb la màxima objectivitat possible, no es van incorporar, a la base de dades, les informacions aparegudes als editorials dels periòdics ni les cartes al director, solament es van analitzar les notícies d'àmbit local. En total, s'hi van incorporar 1.417 notícies referides a 81 conflictes territorials que tingueren lloc durant el període de recerca en el conjunt de municipis que formen l'extint Consell Metropolità de l'Horta.

Sobre cada conflicte, es va realitzar una anàlisi recollint informació sobre sis tipus de variables bàsiques: durada, localització, tipologia, actors, estratègies i resultats. En primer lloc, la durada és la diferència en dies entre la primera notícia i la darrera apareguda en premsa sobre el conflicte en qüestió i corregida amb la informació obtinguda per altres vies, tal com es comentarà després. En segon lloc, la localització és la parcel.la o el territori en el qual s'ubica el projecte o el pla qüestionat. En tercer lloc, es van classificar tots els conflictes en sis tipologies: conflictes per la proximitat, ubicació o distància d'un equipament o d'una infraestructura determinats (que genera o que generarà impactes); conflictes per l'accés a un servei o a un equipament (en aquest cas, demandes veïnals de dotacions bàsiques); conflictes per la protecció del patrimoni cultural, històric o etnològic d'un edifici o d'un territori; en quart lloc, conflictes pel disseny, l'administració o la gestió d'un pla o d'un projecte urbà determinat (conflictes no contra el projecte en si mateix, però sí contra la manera de gestionar-lo i/o d'aprovar-lo); en cinquè lloc, tots els conflictes sorgits per agressions al medi ambient; en sisè lloc, conflictes per activitats o usos del sòl que generen o que poden generar problemes de salut (per contaminació, sorolls i olors, principalment), i, per últim, conflictes per projectes que impliquen una destrucció o una degradació parcial del patrimoni moble, així com l'expulsió d'habitants (expropiacions d'habitatges, majoritàriament per la posada en marxa de plans de reforma interior o la construcció d'infraestructures noves). Seguidament es va inventariar el conjunt d'actors que participaven en cada conflicte dividint-los entre promotors o defensors d'un projecte, d'un pla o d'una decisió territorial (empreses i administracions, principalment), tot recollint les estratègies de defensa. Aquestes estratègies són les accions que han caracteritzat la resistència dels opositors enfront d'un projecte, dividint-les en cinc categories: la participació formal (protesta formal i participació a les fases establertes per al pla); la participació activa (protestes 
i reunions informals, presentació d'al-legacions a un pla); la protesta al carrer (organització de manifestacions i creació de plataformes); les accions legals (presentació de denúncies i processos judicials), i, per últim, les accions il.legals, com ara ocupacions o manifestacions no autoritzades, aücades i violència física o verbal. Ja en darrer lloc, el resultat es refereix a la decisió última i/o definitiva que es pren a instàncies polítiques o judicials sobre un pla, distingint entre l'aprovació final (els interessos dels promotors guanyen), la retirada (els interessos dels opositors prevalen) o la modificació del projecte mitjançant un acord entre els actors enfrontats.

Cal admetre diverses limitacions a l'estudi de conflictes mitjançant la premsa, reconeguts pels mateixos autors de la metodologia de recerca (Trudelle et al., 2006). En primer lloc, cal considerar el biaix ideològic i territorial que presenten gairebé tots els mitjans de comunicació i que, en molts casos, contenen informació fragmentada $\mathrm{i}$ incompleta sobre els esdeveniments que envolten un conflicte territorial. En segon lloc, aquest biaix polític i econòmic no és un problema menor dels mitjans de comunicació espanyols. Tal com afirmen De Miguel i Pozas (2009), el periodisme a Espanya, al contrari que en altres països, té com a trets distintius una forta tradició de periodisme polític, una instrumentalització dels mitjans de comunicació privats, una important politització de les ràdios i televisions públiques i un limitat desenvolupament del periodisme com a professió autònoma. Per tant, es tracta d'una font d'informació com a mínim qüestionable, si no es contrasta amb unes altres. D’altra banda, cal valoritzar-la, ja que l'objectivitat en estudis sobre conflictes territorials no és mai absoluta, a banda del fet que es tracta de l'únic mitjà de comunicació que proporciona informació detallada, periòdica i en una seqüència temporal sobre aquesta temàtica. Així mateix, publicacions de referència sobre planificació territorial, com ara l'Anuari Territorial de Catalunya, empren els periòdics com a font d'informació principal.

En tot cas, com a font secundària d'informació, es va realitzar, d'una banda, un total de deu entrevistes a diferents líders, tant d'associacions de veïns tradicionals com a plataformes, ONG i nous moviments socials urbans de València i de l'àrea metropolitana $(15 \mathrm{M}$, plataforma contra els centres d'internament d'estrangers, etc.). Els resultats d'aquestes entrevistes van ser utilitzats per a completar a la base de dades, sobretot aspectes que no quedaven clars a partir de l'explotació de dades periodístiques, com ara la data de començament i de finalització d'un conflicte, les accions dutes a terme pels opositors o els actors defensors i opositors. Al final del treball, s'inclou el model d'entrevista utilitzat per realitzar-lo. Per últim, com a tercera font de dades, s'ha contrastat la informació recopilada amb la consulta de webs i blogs, tant de moviments socials urbans (plataformes o associacions veïnals), com de webs oficials de projectes i plans urbans, de forma que el resultat final que s'hi analitza a partir de l'apartat següent és fruit de la utilització d'una font primària de dades contrastada amb unes altres dues, en realitat, tres fonts distintes que, segons el nostre parèixer, són suficients per a tindre elements de judici sobre la conflictivitat territorial de València. 
L'àrea d'estudi d'aquest treball contempla el conjunt de municipis que van formar part de l'única administració de caràcter metropolità que ha existit fins hui en dia al País Valencià: el Consell Metropolità de l'Horta. Si bé és cert que aquesta àrea d'estudi no recull la totalitat del fet urbà de València o la ciutat real de València, que s'endinsa prou en altres comarques com ara, sobretot, el Camp del Túria, la Foia de Bunyol i Xiva o fins i tot la Ribera Baixa (Romero, 2008), s'ha intentat com a mínim tenir una fotografia de la geografia de conflictes territorials a l'àrea central d'aquesta. Una línia futura de treball sens dubte seria ampliar la base de dades cap a uns altres territoris que, des del punt de vista de la mobilitat o dels mercats de treball, formen part de la mateixa «ciutat de ciutats», parafrasejant Oriol Nel.lo.

Per últim, com a període d'estudi, s'hi inclou un total de dotze anys entre 2002 i 2013, tots dos inclosos. Encara que es tracta d'un període relativament curt i recent per poder analitzar els conflictes des d'una certa distància i perspectiva temporal, és més que suficient per a poder abordar l'objectiu principal del treball de fer una radiografia de la conflictivitat territorial a València i lligar-la amb dos períodes molt marcats en la història recent del país: el boom urbanístic i especulador del període 1996-2007 i la crisi financera, econòmica i política des de 2008 fins als nostres dies.

\section{Anàlisi de conflictes a l'àrea metropolitana de València}

Tres són les dinàmiques territorials que han caracteritat l'àrea metropolitana de València en els darrers vint anys, periode en el qual s'emmarquen els conflictes ací estudiats: un creixement demogràfic prou notable, sobretot als municipis de la segona corona metropolitana; un canvi en la composició social dels ciutadans, per l'arribada massiva d'immigrants estrangers, i, en tercer lloc, un model de ciutat com a espai de megaprojectes i megaesdeveniments (Sorribes, 2007; Alcalá-Santaella et al., 2011). Hui en dia, l'àrea metropolitana posseeix una població total d'1,6 milions d'habitants aproximadament, enfront de l'1,3 milions que tenia en 2001 (Oficina d'Estadística, 2013). Municipis com ara Paterna augmentaren la seua població un 42\% entre 1996, data d'inici del boom econòmic i urbanístic, i 2012, atès que va passar dels 47.000 als 67.000 habitants actuals. En altres casos, com ara Riba-roja de Túria, fins i tot la població es va duplicar en el mateix període (INE, 2013). Aquest creixement es va basar en un sector terciari en expansió gràcies a l'augment de la mà d'obra a l'Administració, el sector financer, de serveis a empreses o el turisme, però especialment als sectors de la construcció i immobiliari (Alcalá-Santaella et al., 2011:218). Des del punt de vista demogràfic, cal tindre en compte la segona dinàmica esmentada: l'arribada massiva d'immigrants fins a 2008. Mentre que, en 2001, solament el 3,2\% de la població resident era nascuda a l'estranger, hui aquesta població representa quasi un $11 \%$, un percentatge, d'altra banda, que va davallant des de fa anys per l'emigració de població estrangera davant les escasses perspectives de trobar ocupació. En tercer lloc, les formes de creixement escollides per ajuntaments i administracions 
autonòmiques no foren sempre sostenibles ni respectuoses amb el medi ambient, ni tan sols resultat d'una simple improvisació. A partir de 1998 i en consonància amb els corrents internacionals del moment de generació de grans plusvàlues entorn de fites urbanístiques a càrrec d'arquitectes de prestigi, es va inaugurar el nou Palau de Congressos dissenyat per Norman Foster, obra d'autor que donaria lloc a un gran desenvolupament urbanístic en el seu entorn, com és el cas de l'avinguda de les Corts Valencianes. El mateix va succeir amb l'enorme i costosíssima Ciutat de les Arts i les Ciències, al voltant de la qual va nàixer el barri de l'avinguda de França per a classes acomodades, els diversos intents d'expansió i transformació del port a ritme de grans esdeveniments (Fórmula 1 i America's Cup, principalment), el projecte urbà de Sociòpolis sobre l'escassa horta que li quedava a la ciutat de València o el projecte sense executar del Parc Central, amb una arquitecta de renom al darrere (Kathryn Gustafson), encarregada de fer-ne el disseny. No seria exagerat afirmar que la ciutat de València $i$ la seua àrea metropolitana han crescut als darrers vint anys sobretot a colp de grans projectes urbanístics, d'infraestructures i de grans esdeveniments en una filosofia de govern procreixement de progressiva substitució del pla urbanístic pels grans projectes urbans (Díaz, 2010: 282; Gaja, 2006). Prova d'això és que, des de l'aprovació del PGOU de la ciutat en 1988, no s'ha actualitzat el pla, malgrat les nombroses modificacions que ha patit i les transformacions radicals que han experimentat la ciutat i la seua àrea metropolitana.

Malgrat tot, hi ha hagut moltes transformacions urbanes que han sigut qüestionades $\mathrm{amb}$ prou freqüència per la població, però amb una intensitat diferent. Moltes d'aquestes protestes puntuals han donat lloc a conflictes territorials més o menys intensos o llargs, alguns dels quals continuen completament actius ara per ara. Els mapes de les figures 1 i 2 mostren la distribució i la tipologia dels 81 conflictes territorials sorgits a l'àrea metropolitana de València al llarg del període estudiat a partir de la base de dades sobre notícies de conflictes, la informació proporcionada per les entrevistes i la sistematització de variables establerta a l'apartat de metodologia. Atès que és prou complicada la representació gràfica de 81 conflictes a un territori relativament reduït, s'ha optat per numerar-los i nomenar-los amb una paraula clau, tal com es pot observar a la figura 1. A l'annex 1, s'hi pot consultar la llista completa de conflictes amb dos indicadors bàsics d'intensitat: en primer lloc, la quantitat d'articles de premsa escrita publicats sobre el conflicte i el nombre total de paraules que contenen i, de l'altra, el nombre d'estratègies o d'activitats destacades que han estat organitzades al llarg de l'evolució del conflicte pels opositors al projecte o al pla qüestionat. 


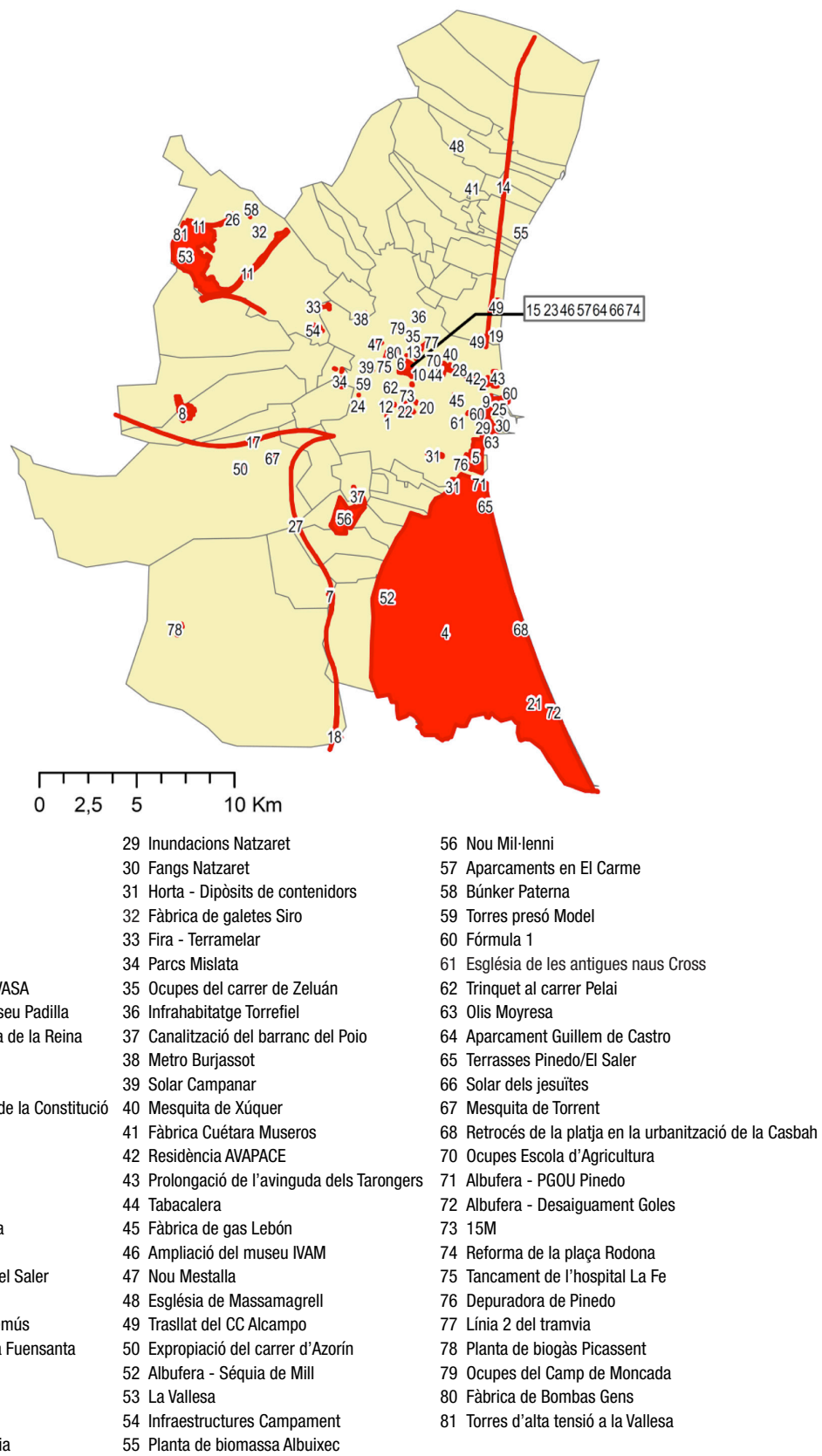

1 Subestació de Patraix

2 Cabanyal

4 Albufera

$5 \mathrm{ZAL}$

6 Convent del Carme

7 AVE - Alcàsser

8 Planta de residus FERVASA

9 Ocupes de la casa museu Padilla

10 McDonald's de la plaça de la Reina

11 Segon bypass

12 Clínica El Consuelo

13 Okupes de l'avinguda de la Constitució

14 AVE - Horta Nord

15 ZAS - Carme

17 AVE - Alaquàs

18 AVE - Picassent

19 Casetes de la Patacona

20 Col-legi a Russafa

21 Reforma del parador del Saler

22 Parc Central

23 Immigrants pont d'Ademús

24 Bancaixa al barri de La Fuensanta

25 Copa Amèrica

26 Institut Paterna

27 AVE - Horta Sud

28 ZAS - Zona Universitària
29 Inundacions Natzaret

34 Parcs Mislata

35 0cupes del carrer de Zeluán

frahabitatge Torrefiel

38 Metro Burjassot

44 Tabacalera

45 Fàbrica de gas Lebón

sllat del CC Alcampo

52 Albufera - Séquia de Mill

54 Infraestructures Campament

55 Planta de biomassa Albuixec
56 Nou Mil·lenn

58 Búnker Paterna

60 Fórmula 1

22 Trinquet al carrer Pelai

65 Terrasses Pinedo/El Saler

66 Solar dels jesuïtes

67 Mesquita de Torrent

70 Ocupes Escola d'Agricultura

$7315 \mathrm{M}$

74 Reforma de la plaça Rodona

Tancament de l'hospital La Fe

78 Planta de biogàs Picassent

79 0cupes del Camp de Moncad

81 Torres d'alta tensió a la Vallesa

Figura 1. Distribució de conflictes territorials a l'àrea metropolitana de València.

Font: elaboració pròpia a partir de la base de dades de conflictes territorials elaborada per l'autor. 


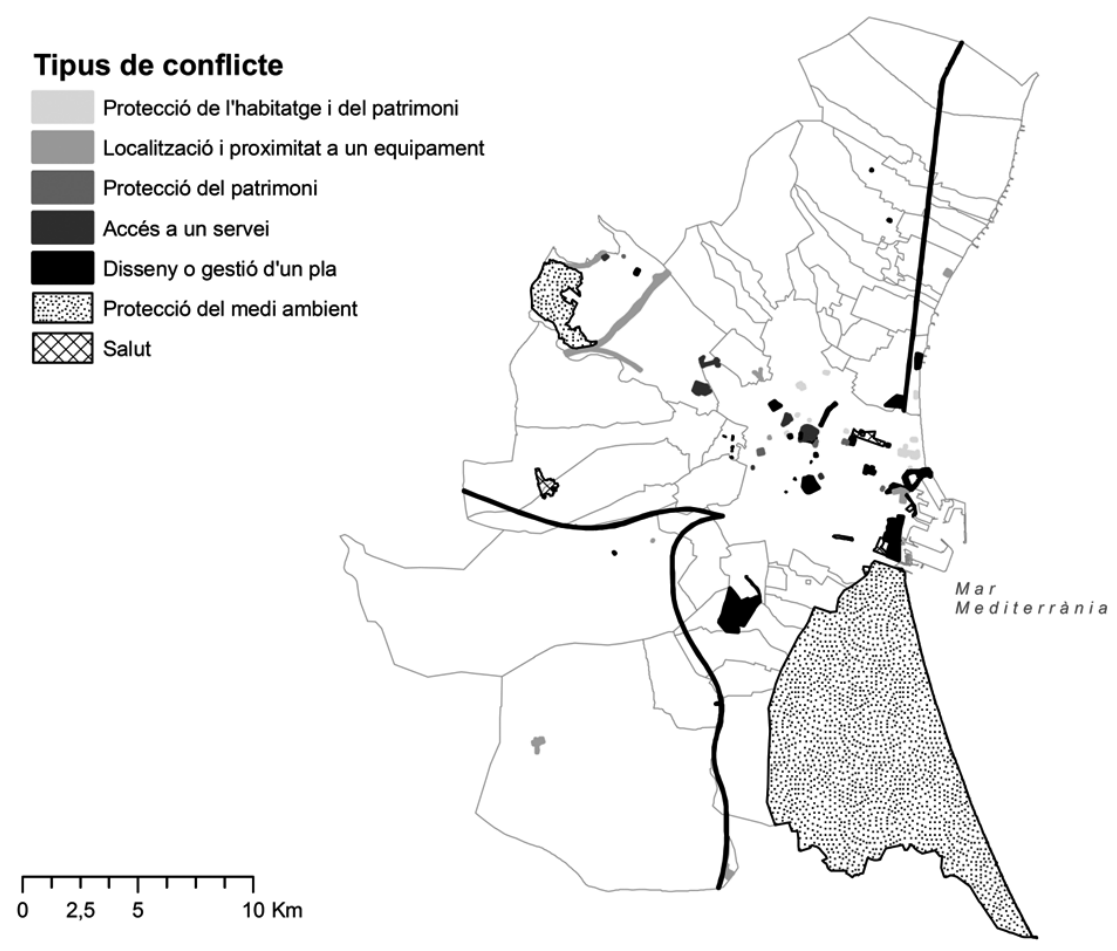

Figura 2. Conflictes territorials segons tipologia a l'àrea metropolitana de València.

Font: elaboració pròpia a partir de la base de dades de conflictes territorials elaborada per l'autor.

Si passem ja a analitzar la geografia dels conflictes, en primer lloc, destaca la concentració que en trobem al municipi central de València, tant al centre històric com a la franja costanera de la ciutat. Sobretot aquesta última ha sigut objecte, als darrers anys, de tot tipus de plans i projectes per transformar aquest territori tradicionalment obrer i desconnectat del centre de la ciutat. D'altra banda, el centre urbà sol ser sempre un focus de conflictivitat territorial. És ací on es concentra una bona part del patrimoni històric de la ciutat, no sempre en bon estat, on sol haver-hi problemes d'equipaments, de circulació i on les administracions tracten, no sempre amb fortuna o garanties d'igualtat, d'iniciar-hi plans i projectes de regeneració urbana que provoquen onades de protestes. Més avall, en veurem algun cas.

Fora de la ciutat, hi destaca sobretot la quantitat de conflictes que sorgeixen per la construcció d'infraestructures noves, en especial, línies d'alta velocitat i autovies. Només l'impacte territorial, així com els moviments de protesta que els projectes ferroviaris i viaris han generat en els darrers anys, podria ser un objecte d'estudi ben interessant. Si bé és cert que qualsevol obra d'aquestes característiques genera sempre malestar per part dels que hi viuen a prop, pels 


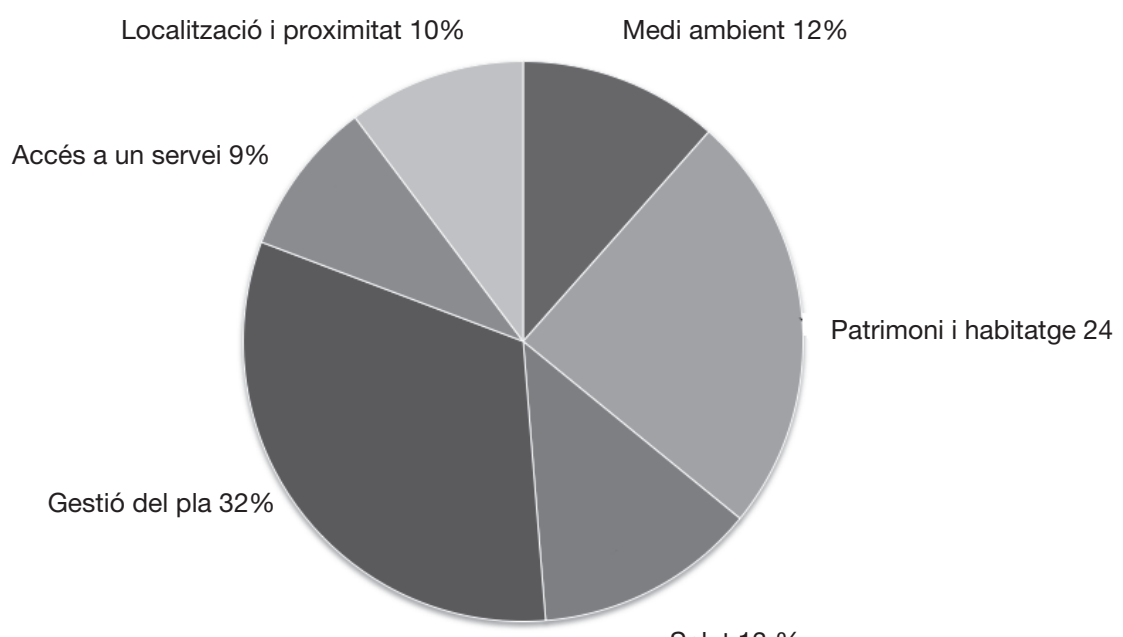

Salut $13 \%$

Figura 3. Conflictes territorials segons tipus (2002-2013).

Font: elaboració pròpia a partir de base de dades de conflictes territorials elaborada per l'autor.

impactes potencials que pot causar, el fet que pràcticament tots els trams de l'AVE que passen per l'AMV hagen desencadenat conflictes, alguns dels quals, per cert, han sigut de gran intensitat, ja ens dóna unes quantes pistes sobre la gestió realitzada d'aquests projectes.

Un altre gran focus de conflictes el constitueixen els espais naturals, en especial aquells que hi ha més a prop de les ciutats. Ací es palesa molt bé el conflicte tradicional d'interessos entre, d'una banda, la conservació del patrimoni natural d'un territori i, d'una altra, les dinàmiques depredadores i especulatives que han caracteritzat el creixement urbanístic valencià. Dos són els espais naturals on han aparegut conflictes amb certa freqüència: l'horta de València i l'Albufera. La primera és qualificada per Romero de "paisatge cultural de valor excepcional» (Romero i Francés, 2012), en el qual han sorgit cinc conflictes de tipus i d'intensitat diferents al llarg del període d'estudi, quasi sempre per la ubicació d'usos no desitjats del sòl (una planta de residus, un centre comercial, la Zona d'Activitats Logístiques, etc.). La segona, l'espai natural protegit legalment des de 1986 del Parc Natural de l'Albufera, on, al llarg dels darrers anys, ha sorgit una vuitena de conflictes relacionats amb problemes de contaminació que encara hui l'agricultura i la indústria generen $\mathrm{o}$ amb la posada en marxa de projectes urbans poc respectuosos amb el caràcter d'aquest espai.

En segon lloc, si analitzem la tipologia dels conflictes (figures 2, 3 i 4), podem comprovar com el grup més nombrós (gairebé un terç) sorgeix per protestes sobre la manera de gestionar un pla, un projecte o una activitat, 


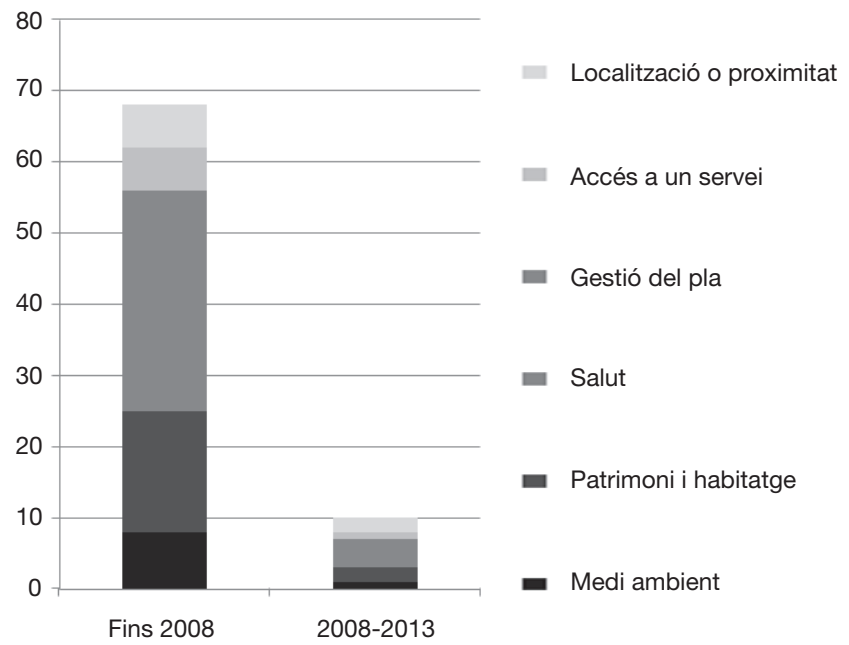

Figura 4. Conflictes territorials per tipus en dos períodes: durant el boom immobiliari i en època de crisi.

Font: elaboració pròpia a partir de base de dades de conflictes territorials elaborada per l'autor.

aprovar-los o executar-los. Això s'observa a la figura 2, ja que molts grans projectes d'infraestructures i equipaments solen ser focus d'enfrontaments per aquesta raó, la qual cosa dóna suport a la hipòtesi que els mecanismes de concertació en planificació no funcionen adequadament, de forma que moltes protestes acaben en conteses més o menys intenses. A més a més, destaca el fet que un $25 \%$ dels conflictes sorgeixen per qüestions relacionades amb el medi ambient o la salut, per tant, respondrien a reaccions davant d'impactes potencials sobre aquestes dues variables vitals per a la qualitat de vida, i un altre $24 \%$ són conflictes sorgits per problemes relacionats amb el patrimoni històric i l'habitatge. En aquesta darrera categoria, hi tenim, com s'ha dit anteriorment, totes aquelles protestes que sorgeixen per plans o projectes que degraden o destrueixen habitatge i patrimoni segons els opositors. Dues de les que han tingut més intensitat al llarg del període estudiat són, d'una banda, el famós i inacabat conflicte per l'ampliació de l'avinguda de Blasco Ibáñez cap al mar i, de l'altra, la construcció d'una zona d'activitats logístiques sobre terrenys d'horta històrica, hui en dia ja executada. El motiu principal de lluita veïnal és que només aquests dos projectes comportarien el desnonament de més de 2.500 persones. En el cas de la ZAL, es va aconseguir dur a terme i, com a conseqüència, més de 620 habitants de la zona hagueren de deixar sa casa malgrat tota la resistència oposada. És més, comprovant la localització de tots els projectes urbans o les decisions que afecten el dret a l'habitatge dels ciutadans, és molt cridaner observar com cap d'aquests projectes es duen a terme en barris de rendes mitjanes o altes, sinó que quasi sempre en surten 
perjudicades les parts més pobres de la ciutat (Poblats Marítims, Benicalap, Benimàmet o Poblats del Sud).

D'altra banda, és interessant introduir la vessant temporal en l'anàlisi de conflictes territorials, si és ben cert que el període estudiat és massa curt i recent per a poder-ne detectar grans tendències. A partir de la lectura de la figura 4, queda clar que el període d'expansió urbanística 2002-2008 va ser el moment de màxima generació de conflictes. Així ho corrobora també la majoria dels entrevistats: els anys de boom urbanístic van ser els de més activitat per als moviments ciutadans contra projectes d'aquest tipus. Només a la ciutat de València, hi figuren, en 2011, 54.000 habitatges més dels que hi havia en 2001 (INE, 2011). La situació en alguns municipis metropolitans és encara més cridanera. En només deu anys, poblacions com ara Alboraia han ampliat el nombre d'habitatges en un 40\%, xifra que s'eleva a un $44 \%$ en el cas de Paterna. Si ho comparem amb l'evolució demogràfica descrita anteriorment, només una part d'aquest creixement s'explica per l'augment de població que $s^{\prime}$ ha produït en aquests municipis. Amb nous milers d'habitatges i amb infraestructures construïdes en poc de temps, el que crida l'atenció és que el nivell de conflictivitat no haja sigut encara més intens. Alguns autors, com ara Gaja, argumenten que, durant el període del boom immobiliari, «molts comportaments i decisions polítiques eren aplaudits per gran part de la ciutadania anestesiada pel consumisme i un fals "efecte riquesa" (Gaja, 2013: 342). A banda d'aquest comportament, prou generalitzat en la societat valenciana, és cert que han sigut moltes les veus que han protestat en desenes de conflictes territorials a l'àrea metropolitana durant aquest període. Si observem la figura 4, 68 de les 81 protestes estudiades tingueren lloc en el període d'esplendor del boom. La segona etapa analitzada (2008-2013) recull només 13 conflictes, que, en comparació són pocs, però la intensitat amb què es van produir va ser alta. Es tracta de conteses relacionades, en alguns casos, amb el moviment $15 \mathrm{M}$, que, després d'ocupar la plaça de l'Ajuntament durant un mes i mig, es va traslladar als barris, on va promoure ocupacions i protestes sobre equipaments, com ara el tancament de l'hospital La Fe al barri de Campanar. Uns altres casos notables són l'ampliació d'una mesquita a Torrent, a la qual s'oposen veïns per problemes d'aparcament, com també l'enderroc de bars a la platja del Saler d'acord amb l'aplicació de la Llei de costes.

\section{El paper de l'Administració i dels moviments socials}

$\mathrm{Si}$, fins ara, hem explorat de manera soma la distribució i la tipologia dels conflictes a l'àrea metropolitana de València, quedaria per a mostrar una imatge general sobre aquest tema, fer una petita menció al paper que, tant moviments socials com administracions, han tingut com a actors molt sovint oposats al llarg d'aquest curt lapse de temps. Si una primera fita en aquest període està constiutida per l'explosió d'una crisi econòmica a València i a tot Espanya, una altra de també important és la irrupció de moviments socials nous, com ara el $15 \mathrm{M}$ o la plataforma contra els desnonaments $(\mathrm{PAH})$. No es tracta de 
col-lectius que actuen en un sol conflicte territorial o que, des d'una òptica o d'una reacció NIMBY, generen una sèrie de protestes, sinó que estem davant d'accions que denuncien tot el procés de presa de decisions, incloses crítiques als mecanismes de democràcia representativa des de l'Administració local fins al Govern central. Aquests moviments proposen estils nous de representació i de participació ciutadana des d'una perspectiva comunitària, de democràcia directa i d'exigència d'un dret a la ciutat (Negri, 2012: 199-200). La totalitat dels moviments veïnals entrevistats consideren el fenomen del $15 \mathrm{M}$ com una aportació molt positiva als col-lectius i a les plataformes de protesta de la ciutat, si bé és cert que veuen el seu futur de manera prou incerta, perquè no disposen d'una estructura ni d'una seu fixa. Després de la seua irrupció mediàtica en maig de 2011, molts dels ciutadans i de les ciutadanes que van estar involucrats en les manifestacions i en les acampades han continuat com a activistes dins de distints moviments de barri, siga reforçant les antigues associacions de veïns que estaven en crisi des de la dècada dels anys vuitanta, siga a través d'associacions de veïns noves o de les mateixes plataformes del $15 \mathrm{M} \mathrm{o} \mathrm{la}$ $\mathrm{PAH}$, tal com afirmen 8 dels 10 entrevistats. En definitiva, l'aparició d'aquests moviments no deixa de ser un pas més del creixent desacord entre ciutadans, d'una banda, i partits polítics i institucions, d'una altra, divorci que, en casos molt similars com el de Catalunya, ja ha sigut analitzat i descrit (Nel.lo, 2003; Subirats, 2011). L'evolució de la protesta ciutadana també en temes territorials respondria, segons Subirats, al fet que hem passat del conflicte social que buscava resposta en el sistema democràtic, a un conflicte social que entén que no hi ha resposta possible sense transformar i modificar també el mateix sistema democràtic, amb la qual cosa es passaria, per tant, del conflicte social al conflicte polític (Subirats, 2011: 115). Aquesta transició és ben palpable en el cas de València. Només cal observar les dues gràfiques següents.

Les figures 5 i 6 són el resultat final de l'anàlisi de l'evolució dels conflictes i de totes les estratègies dutes a terme pels actors que s'oposaren a una decisió, un pla o un projecte determinats dins d'un conflicte. En primer lloc, cal apuntar que els resultats que mostren la figura 5 es refereixen a aquells enfrontaments que es donen per acabats, bé perquè es confirma la decisió o el pla, bé perquè aquest es retira o bé perquè, finalment, s'arriba a un acord. Les xifres parlen per si mateixes sobre la situació de distanciament entre actors existent a València i sobre la fallida quasi generalitzada dels mecanismes de concertació i participació: només en un $13 \%$ dels conflictes s'arribà a una decisió pactada i compartida entre actors, mentre que en més d'un $40 \%$ van ser finalment els interessos dels promotors els que s'acabaren imposant. En la meitat dels conflictes i gràcies, en molts casos, a les grans mobilitzacions protagonitzades per veïns i associacions (problemes de contaminació a l'Albufera denunciats per entitats ecologistes, retirada del projecte de trasllat d'un centre comercial al bell mig de l'horta o del projecte d'urbanització Nou Mil.lenni a Catarroja), van ser els interessos dels oponents els que es van imposar. A més, dins del $20 \%$ de conteses on preval l'interès de l'oponent, s'hi inclouen uns altres tipus d'enfrontaments urbans, com ara les ocupacions, on, d'una banda, 


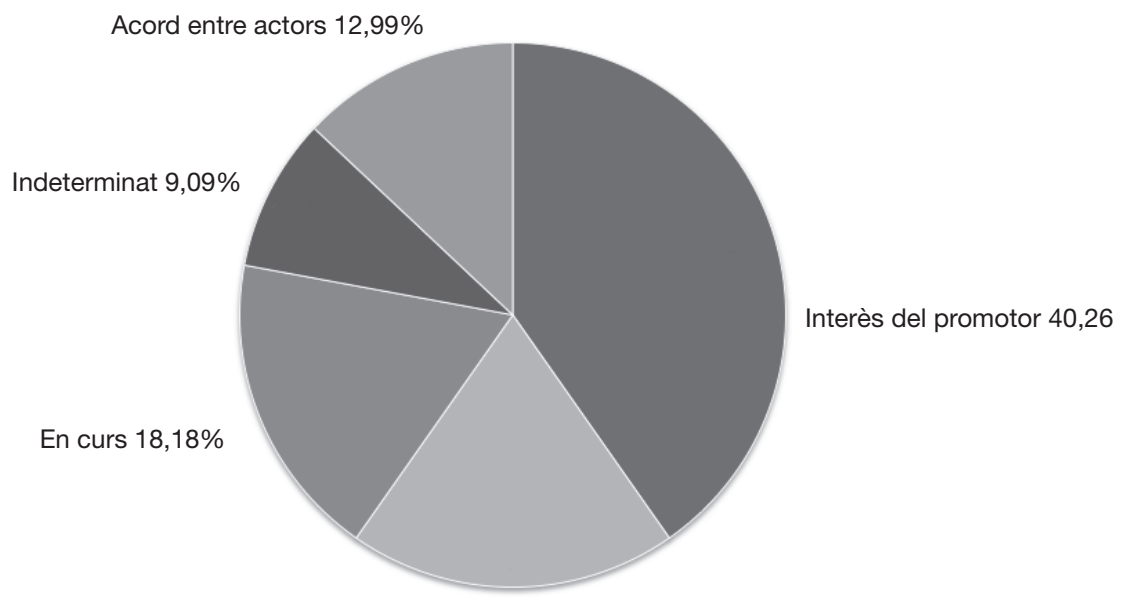

Interès de l'oponent $19,48 \%$

Figura 5. Resultat final dels conflictes a l'àrea metropolitana de València (2002-2013).

Font: explotació base de dades de conflictes territorials elaborada per l'autor.

hi ha un grup que ocupa físicament un espai normalment privat, mentre que veïns i administracions lluiten perquè es desocupe. D’aquesta manera, si només tenim en compte els conflictes en els quals un pla o un projecte de tipus urbà o territorial ha sigut finalment rebutjat o retirat per la pressió ciutadana, ens quedaríem amb menys d'una desena de casos.

A part d'això, la figura 6 palesa el nou escenari de confrontació política creixent en el qual estem immersos. Aquesta imatge fa una divisió dels conflictes segons el tipus d'estratègia més intensa posada en marxa en cadascun, com s'ha explicat a l'apartat de metodologia. De nou, és molt interessant comprovar com la participació formal dins dels canals institucionals de comunicació entre actors són estratègies emprades només en un 5\% dels casos. Per contra, és com a mínim sorprenent que la segona estratègia més emprada en els conflictes, només per darrere de les manifestacions, és la constituïda per les accions il.legals, grup d'estratègies que, en algun moment, van aparèixer en un $30 \%$ de totes les conteses. Tampoc és menyspreable el 14\% d'enfrontaments que terminen en els tribunals. Aquest traspàs freqüent al sistema judicial d'un problema originat des de l'àmbit polític i de la planificació denota, un colp més, que els procediments de planificació i govern del territori generen un gran descontentament social. Fins i tot, més que de descontentament, caldria parlar d'injustícia ambiental i de predació de recursos, quan veiem sistemàticament que tots els plans que comporten greus impactes territorials (Fórmula 1, subestació elèctrica, grans infraestructures i vies de comunicació) afecten, sobretot, barris o territoris fràgils i amb població de classes baixes. També caldria parlar de l'enorme destrucció que molts projectes urbans han causat sobre el patri- 


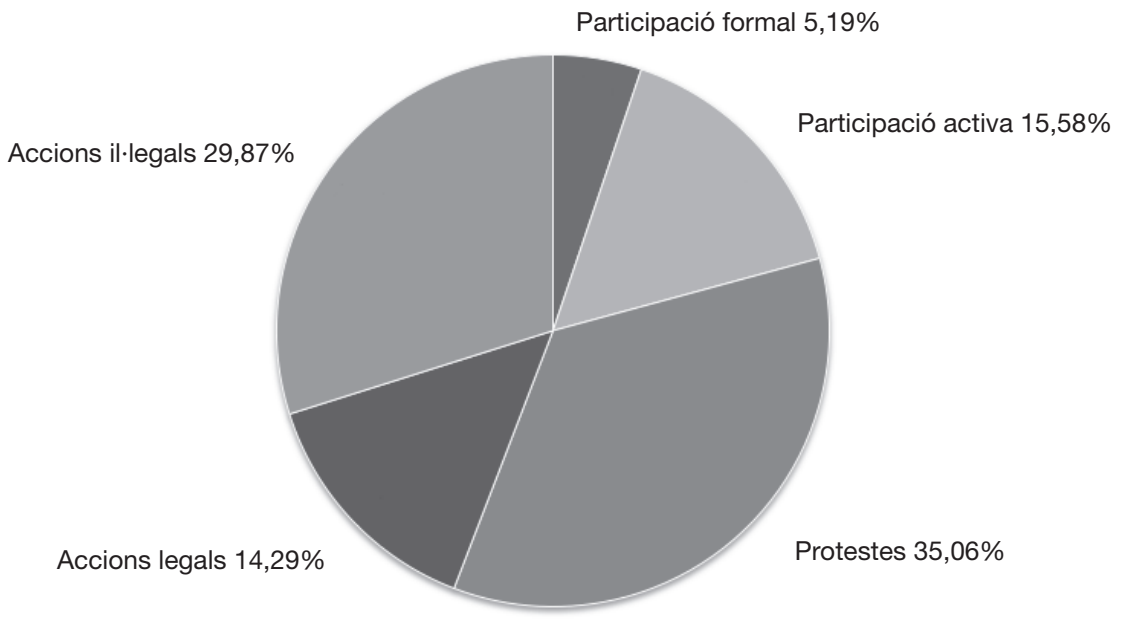

Figura 6. Estratègies d'oposició que caracteritzen cada conflicte.

Font: explotació de base de dades de conflictes territorials elaborada per l'autor.

moni històric, aspecte especialment visible en el centre, que explica per què aquesta zona és la més activa en conflictes: plans d'aparcament que amenacen jaciments romans; ampliació del museu IVAM a un antic convent; reformes controvertides pel seu disseny trencador, com ara la plaça Rodona, etc. En definitiva, València viu uns quants anys d'activisme social molt intensos, que es manifesten mitjançant l'estudi de conflictes territorials.

\section{Conclusions}

Aquest treball ha consistit en una anàlisi geogràfica dels conflictes territorials existents a València i en una descripció breu dels actors que hi han participat, a partir de l'explotació d'una base de dades de 81 conflictes elaborada seguint fonts periodístiques. L'estudi s'emmarca en un periode curt però intens de transformacions urbanes i territorials, en el qual sorgeix un bon munt de conflictes lligats a l'ús del sòl protagonitzats per moviments ciutadans hereus dels moviments veïnals dels anys setanta, amb demandes i discursos nous.

Es podria afirmar que, més que una radicalització dels moviments ciutadans a València, el que ha esdevingut en la darrera dècada és un distanciament continu entre capes creixents de la ciutadania i el govern de les ciutats de l'àrea metropolitana de València i un fracàs dels mecanismes de concertació en planificació. Molts projectes amb forts impactes territorials van aprovar-se finalment sense tenir en compte cap veu crítica o dissident: la famosa ZAL del port, la pista de Fórmula 1, les línies d'alta velocitat, per no mencionar el llarg conflicte del Cabanyal. 
En aquest punt, cal recuperar el concepte de conflicte proposat en aquest treball com un component necessari de tota societat. El fet en si mateix que, a València, hi haja conflictes ja ha de donar una certa esperança de veure una ciutat on moltes decisions preses sobre la seua gestió són, com a mínim, contestades per alguns. Tota proposta a partir d'aquesta situació de confrontació intensa hauria d'anar encaminada sobretot a redefinir els marcs de relacions entre ciutadans i representants públics, més que no pas a proposar mesures que ajuden a amagar conflictes o a evitar-ne. En aquest sentit, la senda que cal emprendre en els pròxims anys passa per recompondre les relacions hui en dia trencades entre actors socials i polítics, com també pel reconeixement institucional del fet que la planificació territorial, urbana i sectorial desplegada en els darrers anys ha sigut molt allunyada dels interessos d'alguns ciutadans per dedicar-se a satisfer certs interessos lligats als sectors de la construcció, l'immobiliari i els de prestació privada de serveis. En el fons, el que aquestes protestes evidencien és la manifestació espacial de les profundes contradiccions del sistema capitalista en les ciutats i, en aquest sentit, és difícil plantejar alternatives que, més que reformistes, siguen trencadores com a mínim amb el sistema de representació parlamentària i de participació ciutadana actual. En tot cas, hauria de ser una prioritat a l'agenda política dels municipis de l'àrea metropolitana fer la diagnosi de deu anys de conflictes territorials com l'ací presentada.

\section{Referències bibliogràfiques}

Alcalá-Santaella, Felipe; Díaz Orueta, Fernando; Ginés, Xavier i Lourés, M. Luisa (2011). «Una nueva agenda urbana para las grandes ciudades: Crecimiento y competitividad». A: Iglesias, Mariela; Martí-Costa, Marc; Subirats, Joan i Tomás, Mariana (eds.). Politicas urbanas en España: Grandes ciudades, actores y gobiernos locales. Barcelona: Icaria.

Alfama, Eva; Casademunt, Àlex; Coll-Planas, Gerard; Cruz, Helena i Martí, Marc (2007). Per una nova cultura del territori?: Mobilitzacions i conflictes territorials. Barcelona: Icaria Antrazyt.

Bobbio, Luigi i Zeppetella, Alberico (1999). Perch'e proprio qui?: Grandi opere e opposizioni locale. Milà: Franco Angeli.

BrIon, Denis J. (1988). «An Essay on LULU, NIMBY, and the problem of distributive Justice». Boston College of Environmental Affairs Law Review, 15 (3/4), 437.

Cox, Kevin R. (dir.) (1978). Urbanization and conflict in market societies. Londres: Methuen.

Cox, Kevin R.; Johnston, Ron (dirs.) (1982). Conflicts, politics, and the urban scene. Nova York: St. Martin's Press.

Cucó, Josepa (2013). «Poniendo a Valencia en el mapa global: Políticas, desarrollos urbanos y narrativas sobre la ciudad». A: Cucó, Josepa (ed.). Metamorfosis urbanas: Ciudades españolas en la dinámica global. Barcelona: Icaria / Institut Català d'Antropologia, 157-180.

DAHRENDORF, Ralf (1958). «Out of utopia: Toward a reorientation of sociological analysis». American Journal of Sociology [en línia], 64 (2), 115-127.

<http://dx.doi.org/10.1086/222419> 
DeAR, Michael (1992). "Understanding and overcoming the NIMBY syndrome». Journal of the American Planning Association [en línia], 58 (3), 288-300. <http://dx.doi.org/10.1080/01944369208975808>

DíAz, Fernando (2010). «Regímenes urbanos y movimiento ciudadano en Valencia». Cuaderno Urbano: Espacio, Cultura, Sociedad, 9 (9), 275-294.

Dolç, Carles i SANCHO, Josep Maria (2003). «L'illa de Jesuïtes: La ciutadania i el paisatge també compten». A: GaJA, F. (ed.). Pensar València: Taller XXI d'urbanisme. València: UPV.

DunN, Bill (2007). «Accumulation by dispossession or the accumulation of capital: The case of China». Journal of Australian Political Economy, 60, 5.

GajA, Fernando (2006). «El boom de València o la ciutat com a espectacle». A: Llibre Verd del Territori Valencià. València: Escola Valenciana / Federació d'Associacions per la Llengua.

- (2013). «Tras el tsunami inmobiliario: Salir del atolladero». A: Paisajes devastados. Después del ciclo inmobiliario: impactos regionales y urbanos de la crisis. Madrid: Traficantes de Sueños, 273-309. Observatorio Metropolitano.

García, Pedro i Ruiz, Miquel Àngel (2013). «Degradación, espectacularización y espacios del miedo: El Cabanyal». A: Cucó, J. (ed.). Metamorfosis urbanas: Ciudades españolas en la dinámica global. Barcelona: Icaria / Institut Català d'Antropologia, 353-376.

Harvey, David (2005). A Brief History of Neoliberalism. Oxford: Oxford University Press.

Instituto Nacional de Estadística (2011). «Censo de población y viviendas de 2011» [en línia] <http://www.ine.es/inebmenu/mnu_cifraspob.htm>.

Janelle, Donald G. (1977). «Structural dimensions in the geography of locational conflicts». Le Géographe Canadien, 21, 311-328.

Janelle, Donald. G. i Millward, Huge (1976). «Locational conflict patterns and urban ecological structure». Tijdschrift voor Economishe en Sociale Geografie [en línia], 67 (2), 102-113. <http://dx.doi.org/10.1111/j.1467-9663.1976.tb01391.x>

LeCardane, Renzo (2008). «Le front de mer de Valencia et l'héritage de l'America's Cup 2007». Méditerranée [en línia]. <http://mediterranee.revues.org/2827, 111> [Consulta: 12 març 2014].

Lecourt, Arnaud i Baudelle, Guy (2004). «Planning conflicts and social proximity: A reassessment». International Journal of Sustainable Development, 7 (3), 287-301.

LeY, David i Mercer, John (1980). "Locational conflict and the politics of consumption». Economic Geography, 56, 89-109.

Mateu, Anna i Domínguez, Mateu (2011). «Inicios del columnismo ambiental en la prensa española: La campaña de Las Provincias sobre la urbanización de El Saler (Valencia, España)». Zer: Revista de Estudios de Comunicación, 30, 171-187.

Miguel, Juan Carlos de i Pozas, Víctor (2009). "¿Polarización ideológica o económica?: Relaciones entre los medios y el poder político y corporativo». Viento Sur, 103, maig, 43-52.

Moral, Leandro del (1994). «Elementos para una teoría de los conflictos territoriales sobre el agua». Boletín de la AGE, 18, 17-27.

Negri, Antonio (2012). Il comune in rivolta: Sul potere costituente delle lote. Verona: Ombre Corte. UniNomade.

NeL.Lo, Oriol (2003). Aqui no!: Els conflictes territorials a Catalunya. Barcelona: Empúries. 
Newton, Kevin (1978). "Conflict avoidance and conflict suppression: The case of urban politics in the United States». A: Cox, Kevin R. (ed.). Urbanization and conflict in market societies. Londres: Maaroufa Press, 76-93.

Popper, Frank J. (1981). «Sitting LULUs». Planning, 47 (4), 12-15.

Romero, Joan i Francés, Miquel (2012): La huerta de Valencia: Un paisaje cultural con futuro incierto. València: PUV.

Romero, Luis del (2008). Planificació i govern del territori a l'Arc Mediterrani Espanyol. València: PUV.

- (2010). «Dos décadas de urbanismo-espectáculo en España: Los grandes eventos como motor de cambio urbano». Boletín de la Asociación de Geógrafos Españoles, 53, 309-327.

- (2014). «Urban unrest and new social movements: Lessons from Spain». A: Conflicts in the city: Reflections on urban unrest international congress. València, 2 d'abril de 2014.

Sorribes, Josep (2001). "El malestar urbà a València: A propòsit dels "Salvem”". Mètode, 31.

- (2007). Les Valències: L'urbs polièdrica. València: Faximil.

Subirats, Joan (2011). "¿Qué democracia tenemos?: ¿Qué democracia queremos?». Historia Actual On Line, 26 (tardor), 115-132.

Torres, Vicent (2004). "Nuevos y viejos movimientos ciudadanos en el País Valenciano". A: Movimientos sociales hoy: avanzando hacia una democracia transformadora. Universitat d'estiu Rafael Altamira, Alacant. [en línia]: <http://www. univerano.ua.es/es/cursosprevios/cursos2004/movimientos/torresconf.pdf>.

Trudelle, Catherine; Thériault, Marius; Pelletier, Mathieu i Villeneuve, Paul (2004). Répertoire des conflits urbains, RMR de Québec, 1965-2000. Québec: Université Laval, CRAD.

Trudelle, Catherine; Villeneuve, Paul; Thériault, Marius i Pelletier, Mathieu (2006). "Becoming Visible: Women and Conflicts in the Quebec Metropolitan Area, 1965-2000». Urban Studies [en línia], 43 (13), 2183-2203. <http://dx.doi.org/10.1080/00420980600936533>

\section{Fonts}

Instituto Nacional de Estadística (2013). Padrón contínuo de habitantes [en línia]. <http://www.ine.es/jaxi/menu.do? $\mathrm{L}=0 \&$ type $=$ pcaxis $\&$ path $=\% 2 \mathrm{Ft} 20 /$ e245\&file=inebase> [Consulta: 12 juny 2014].

Oficina d'Estadística de l'Ajuntament de València (2013). Dades de població de l'àrea metropolitana [en línia].

<http://www.valencia.es/ayuntamiento/estadistica.nsf/vDocumentosTituloAux /\%C3\%81 rea\%20Metropoitana?opendocument\&lang=2\&nivel=5> [Consulta: 21 juny 2014]. 


\section{Annex 1}

Llista completa de conflictes amb tres variables bàsiques

\begin{tabular}{|c|c|c|c|c|}
\hline Id_Conflit & Nom del conflicte & Articles & Paraules & Esdeveniments \\
\hline 1 & Subestació elèctrica de Patraix & 41 & 14.278 & 48 \\
\hline 2 & Ampliació de Blasco Ibáñez al Cabanyal & 62 & 31.372 & 60 \\
\hline 4 & Contaminació de l'Albufera & 15 & 6.115 & 13 \\
\hline 5 & ZAL & 19 & 7.927 & 25 \\
\hline 6 & Convent del Carme & 10 & 4.510 & 8 \\
\hline 7 & AVE - Alcàsser & 8 & 4.255 & 8 \\
\hline 8 & Planta de residus FERVASA & 12 & 4.812 & 11 \\
\hline 9 & Ocupes de la casa museu Padilla & 14 & 5.408 & 16 \\
\hline 10 & McDonald's de la plaça de la Reina & 2 & 493 & 2 \\
\hline 11 & Construcció d'autovia a Paterna & 20 & 7.032 & 28 \\
\hline 12 & Clínica El Consuelo & 14 & 4.408 & 14 \\
\hline 13 & Ocupes de l'avinguda de la Constitució & 3 & 1.640 & 3 \\
\hline 14 & AVE - Horta Nord & 4 & 2.013 & 4 \\
\hline 15 & ZAS - Carmen & 13 & 4.340 & 13 \\
\hline 17 & AVE - Alaquàs & 2 & 1.203 & 3 \\
\hline 18 & AVE - Picassent & 2 & 693 & 2 \\
\hline 19 & Casetes de pescadors de la Patacona & 3 & 1.381 & 3 \\
\hline 20 & Demanda de col-legi a Russafa & 5 & 1.204 & 5 \\
\hline 21 & Reforma parador del Saler & 9 & 4.127 & 9 \\
\hline 22 & Parc Central & 6 & 3.435 & 6 \\
\hline 23 & Immigrants al Pont d'Ademús & 13 & 5.260 & 13 \\
\hline 24 & Bancaixa al barri de La Fuensanta & 2 & 1.003 & 3 \\
\hline 25 & Copa Amèrica & 3 & 1.108 & 3 \\
\hline 26 & Institut de Paterna & 4 & 1.472 & 4 \\
\hline 27 & AVE - Horta Sud & 11 & 4.611 & 10 \\
\hline 28 & ZAS - Zona Universitària & 9 & 4.257 & 9 \\
\hline 29 & Inundacions a Natzaret & 10 & 3.717 & 10 \\
\hline 30 & Fangs Natzaret & 2 & 347 & 2 \\
\hline 31 & Dipòsits de contenidors a l'Horta & 3 & 870 & 2 \\
\hline 32 & Fàbrica de galetes Siro & 6 & 2.227 & 6 \\
\hline 33 & Fira de Mostres - Terramelar & 4 & 1.612 & 3 \\
\hline 34 & Parc de Mislata & 6 & 2.122 & 6 \\
\hline 35 & Ocupes del carrer de Zeluán & 7 & 2.227 & 5 \\
\hline 36 & Infrahabitatges a Torrefiel & 3 & 622 & 2 \\
\hline 37 & Canalització del barranc del Poio & 4 & 1.296 & 4 \\
\hline 38 & Metro Burjassot & 7 & 2.447 & 10 \\
\hline 39 & Solar Campanar & 2 & 1.074 & 3 \\
\hline 40 & Mesquita de Xúquer & 12 & 4.558 & 15 \\
\hline 41 & Fàbrica Cuétara de Museros & 12 & 4.360 & 16 \\
\hline 42 & Residència AVAPACE & 12 & 4.155 & 13 \\
\hline 43 & Prolongació de l'avinguda dels Tarongers & 5 & 2.011 & 6 \\
\hline 44 & Reforma de Tabacalera & 8 & 3.245 & 9 \\
\hline
\end{tabular}




\begin{tabular}{clrrr}
\hline Id_Conflit & \multicolumn{1}{c}{ Nom del conflicte } & Articles & Paraules & Esdeveniments \\
\hline 45 & Gas Lebón & 2 & 409 & 2 \\
46 & Ampliació del museu IVAM & 8 & 3.625 & 9 \\
47 & Estadi Nou Mestalla & 18 & 8.743 & 18 \\
48 & Església de Massamagrell & 15 & 5.827 & 16 \\
49 & Trasllat del CC Alcampo & 8 & 2.416 & 8 \\
50 & Expropiació al carrer Azorín & 7 & 3.129 & 10 \\
52 & Albufera - Séquia de Mill & 3 & 1.110 & 4 \\
53 & La Vallesa & 10 & 3.399 & 9 \\
54 & Infraestructures Campamento & 4 & 1.227 & 4 \\
55 & Planta de biomassa Albuixec & 5 & 1.969 & 5 \\
56 & Nou Mil-lenni & 9 & 3.364 & 9 \\
57 & Aparcaments en El Carme & 12 & 3.955 & 12 \\
58 & Búnker a Paterna & 3 & 885 & 2 \\
59 & Torres de la presó Model & 2 & 1.168 & 2 \\
60 & Fórmula 1 & 19 & 7.935 & 23 \\
61 & Nova església a les antigues naus Cross & 7 & 2.647 & 7 \\
62 & Trinquet al carrer Pelai & 3 & 1.340 & 4 \\
63 & Fàbrica d'olis Moyresa & 3 & 741 & 3 \\
64 & Aparcament a Guillem de Castro & 4 & 1.889 & 4 \\
65 & Terrasses a Pinedo/El Saler & 20 & 10.221 & 19 \\
66 & Solar dels jesuïtes & 6 & 3.027 & 6 \\
67 & Mesquita de Torrent & 12 & 5.668 & 10 \\
68 & Erosió per la urbanització de la Casbah & 6 & 3.805 & 6 \\
70 & Ocupes Escola d'Agricultors & 5 & 2.666 & 6 \\
71 & Albufera - PGOU Pinedo & 5 & 3.369 & 5 \\
72 & Albufera - Contaminació de les Goles & 4 & 1.987 & 6 \\
73 & 15M & 5 & 8.247 & 14 \\
74 & Reforma de la plaça Rodona & 2.110 & 5 \\
75 & Tancament de l'Hospital de La Fe & 7 & 3.338 & 7 \\
76 & Depuradora de Pinedo & 4 & 1.959 & 4 \\
77 & Línia T2 del tramvia & 3 & 556 & 3 \\
78 & Planta de biogàs de Picassent & 5 & 2.580 & 5 \\
79 & Ocupes Camí de Moncada & 2.712 & 2 \\
80 & Fàbrica Bombas Gens & & & 6 \\
81 & Torres d'alta tensió a la Vallesa & 5 & 5 \\
\hline & & 5 &
\end{tabular}




\section{Annex 2}

Model d'entrevista passat a les associacions de veïns i plataformes següents: Benicalap, Benimaclet, Plataforma Salvem el Cabanyal, El Grau-Platja, Jarit, Malilla, Patraix, Plataforma anti CIE, Xarxa de Solidaritat Popular, Moviment $15 \mathrm{M}$ i Russafa.

1. Per què es va crear l'associació?

2. Temps d'activitat

3. Camp d'acció i abast territorial de l'associació

4. Opinió sobre els conflictes més actius del barri

5. Perfil social de les persones que formen part de l'associació

6. Vincles amb altres associacions

7. Principals objectius aconseguits

8. Enumere els conflictes territorials més destacables de la ciutat

9. Relació i tipus de vincle de l'associació amb el $15 \mathrm{M}$

10. Valoració personal sobre el futur de l'associació i del 15M 